\title{
Assortment of kaempferol and zinc gluconate improves noise-induced biochemical imbalance and deficits in body weight gain
}

\author{
Isaac Oluwatobi Akefe ${ }^{1,2 *}$ (D), Joseph Olusegun Ayo $^{2}$ and Victor Olusegun Sinkalu ${ }^{2}$ \\ ${ }^{1}$ Department of Physiology, Biochemistry and Pharmacology, Faculty of Veterinary Medicine, University of Jos, Nigeria, and \\ ${ }^{2}$ Department of Physiology, Faculty of Veterinary Medicine, Ahmadu Bello University, Zaria, Nigeria \\ *Corresponding author. Email: i.akefe@uq.edu.au
}

(Received 14 August 2021; Revised 22 September 2021; Accepted 08 November 2021)

\begin{abstract}
This study investigated the effects of pretreatment with antioxidants, kaempferol, and zinc gluconate on serum biochemical changes and impairment in body weight gain following noise-exposure in Wistar rats. Thirty-five animals were evenly grouped into five cohorts: Groups II, III, IV, and V were exposed to noise stress, induced by exposing rats to $100 \mathrm{~dB}$ ( $4 \mathrm{hr} /$ day) for 15 days, from days 33 to 48 after starting the drug treatments. Treatment with kaempferol and/or zinc mitigated noise-induced deficits in body weight gain, and levels of serum lipid and protein fractions. The combined treatment significantly $(p<.05)$ decreased malondialdehyde concentration in kaempferol + zinc gluconate treated group, compared to the group administered deionized water + noise. This result demonstrates that biochemical dyshomeostasis and lipid peroxidation may be involved in the molecular mechanism underlying noise stress and the assortment of kaempferol and zinc gluconate produced an improved mitigating outcome in Wistar rats.
\end{abstract}

Key words: biochemical; bodyweight; kaempferol; noise; oxidative stress; Wistar rats; zinc

\section{Introduction}

A remarkable rise in the reports of noise-associated health perturbations, especially in metropolitan environments with high level of industrialization have been documented in several recent studies (GBD 2019 Hearing Loss Collaborators, 2021). Excessive noise exposure has been shown to disrupt physiological homeostasis, consequently eliciting a cascade of pathological responses prominent among which is hearing loss, diabetes mellitus, aging related stroke, and cardiovascular disease (Floud et al., 2013; Liu et al., 2018). In addition, continuous subjection to loud noise has been shown to impair growth and significantly decrease the weight of some vital organs in the exposed animals (Jalali et al., 2012). Moslehi et al. (2010) reported that noise may interfere with animal appetite by decreasing the secretion of saliva and gastric fluids, consequently impeding intestinal motility and rate of digestion. Furthermore, noise exposure has been shown to trigger alteration in serum biochemical parameters, DNA damage, and loss of neuronal function (Akefe et al., 2020; Ji et al., 2019).

Antioxidants are beneficial in ameliorating the adverse effects induced by noise stress via scavenging free radicals and reducing them to less harmful molecules (Marreiro et al., 2017). The flavonoid, kaempferol belongs to the family Zingiberaceae (Bigoniya et al., 2013) and can be sourced from horseradish, green cabbage, green beans, spinach, olive oil, amaranth, aloe-vera, tea, apple, lettuce, grapes, strawberries, 
onions, cowpea, broccoli, and leek (Langeswaran et al., 2018). Zinc is a divalent cation, involved in many biochemical and physiological body functions in mammals (Prasad, 2014). Zinc plays a vital modulatory role in the nervous system and notably prevents inhibition mediated by gamma-aminobutyric acid (GABA) by impeding the GABA-A receptor (Andreini \& Bertini, 2012). Although antioxidant assortment has been suggested to yield synergistic effects in treating different conditions (Yasuno et al., 2012), no study is yet to evaluate the effects of combining both metal and flavonoid antioxidants in ameliorating noiseinduced deficits in body weight gain and biochemical imbalances in Wistar rats.

\section{Objectives}

Our objective was to determine the changes in body weight gain and biochemical parameters in Wistar rats administered with kaempferol and zinc gluconate and exposed to ambient noise of approximately $100 \mathrm{~dB}$. We hypothesized that supplementation of kaempferol and gluconate either alone or in combination would be beneficial to ameliorate the negative effects of noise stress in Wistar rats. To examine this hypothesis, we assessed serum biochemical parameters and percentage body weight gain in separate groups of Wistar rats given these antioxidants alone and in combination.

\section{Methods}

\subsection{Ethics statement}

The Ahmadu Bello University Committee on Animal Use and Care reviewed and approved all animal procedures (ABUCAUC No.: 02/17/22) in conformity with the National Institutes of Health guide for the care and use of laboratory animals.

\subsection{Animals and experimental protocol}

Thirty-five 7-week-old male Wistar rats (120 and $125 \mathrm{~g}$ ) were utilized in this experiment. They were maintained in plastic cages under acceptable laboratory conditions. The rats were examined for health and pathogen-free status and subjected to minimum stress or discomfort throughout the experimental period by ensuring minimal handling. The rats were fed with standard commercially prepared rat pellet and water ad libitum. The animals were randomly grouped into five cohorts of seven rats each as follows: Groups I and II were administered with deionized water; Group III, kaempferol; Group IV, zinc gluconate; Group V, kaempferol + zinc gluconate for 34 days. Groups II, III, IV, and V were subjected to noise stress of $100 \mathrm{~dB}$ dose daily for $4 \mathrm{hr}$ per day and for 15 days consecutively, from days 33 to 48 of the experimental period. At the end of the experiment, the animals were anaesthetized by injection of ketamine + xylazine $65 / 4 \mathrm{mg} / \mathrm{kg}$, i.p. and then sacrificed by severing the jugular. Blood was collected from all the rats and thereafter, serum was retrieved and maintained at $4^{\circ} \mathrm{C}$ for further analysis.

\subsection{Drug and dosage}

Kaempferol and zinc gluconate (Aldrich Chemical Co. Ltd., Gillingham Dorset, England, Cat. No. 25,556-4) were reconstituted in deionized water and administered orally at a dose of $5 \mathrm{mg} / \mathrm{kg}$ body weight (Bigoniya et al., 2013; Isaac, Joseph, et al., 2017) and $50 \mathrm{mg} \mathrm{zinc/kg}$ body weight (Saki et al., 2016) respectively, while the controls were given deionized water $(2 \mathrm{ml} / \mathrm{kg}$ body weight).

\subsection{Noise stress induction}

Briefly, noise was produced by a loudspeaker $(15 \mathrm{~W})$, mounted $30 \mathrm{~cm}$ over the cages, and propelled by a white noise generator (DT-8850; Shenzhen Technology Co. Ltd., Shenzhen, Guangdong, China). The sound intensity was uniformly maintained at $100 \mathrm{~dB}$ using a precision sound level meter (Voltcraft SL-200, 
Hirschau, Germany). During the experiment, the noise level peaked at $100 \mathrm{~dB} / 4 \mathrm{hr} / \mathrm{day}$ for 15 days (Akefe et al., 2020; Wankhar et al., 2014). Throughout the noise exposure, the control group was kept in a different room with the uniform baseline noise level, and once the noise was switched off, they were returned to the same room with the other groups.

\subsection{Measurements}

Body weights of all the rats were recorded on days 0,8 , and 15 (following the beginning of noise exposure) using a weighing scale (Scaltec SPO-62; Scaltec Instruments; sensitivity: 0:1 g) and expressed in percentage. The concentrations of total protein, albumin, globulin, cholesterol, triglyceride, low density lipoproteins, high density lipoproteins, and electrolytes $\left(\mathrm{K}^{+}, \mathrm{Na}^{+}, \mathrm{Cl}^{-}, \mathrm{HCO}_{3}{ }^{-}\right)$were determined using an automated haematologic analyser (Selectra Junior Spinlab 100, Vital Scientific, Dieren, Netherlands; Spinreact, Girona, Spain) according to the manufacturers' instructions. Standard controls were run prior each determination, and the values obtained for the different biochemical parameters were always within the normal ranges. To determine the concentration of malondialdehyde, we used the method described by Draper and Hadley (1990). The spectrophotometric evaluation of color change during the reaction between thiobarbituric acid (TBA) and malondialdehyde (MDA) was performed. The level of MDA was assessed via the absorbance coefficient of MDA-TBA complex $1.56 \times 10^{5} / \mathrm{cm}$, calculated in $\mathrm{nmol} / \mathrm{mg}$ protein.

\subsection{Statistical analysis}

Data derived from this study were expressed as mean \pm standard error of mean $( \pm$ SEM). Values were subjected to one-way analysis of variance (ANOVA), followed by Tukey's post hoc test to evaluate significance of the difference between the group means. GraphPad Prism was used to analyze all the data and values of $p<.05$ were considered significant.

\section{Results}

\subsection{Effect of treatments on body weight changes}

Noise exposure significantly $(p<.05)$ decreased the percentage body weight gain. Conversely, administration of kaempferol and zinc gluconate singly, and in combination significantly $(p<.05)$ improved percentage body weight gain (Figure 1).

\subsection{Effects of treatments on serum electrolytes concentration}

The individual serum electrolyte concentrations in the DW $+\mathrm{N}$ group decreased marginally when compared to the other treatment groups, however, this change was not significant $(p>.05)$ between the groups (Figure 2).

\subsection{Effect of treatments on glucose concentration}

There was a significant $(p<.05)$ decrease in serum glucose concentration in the groups treated with DW, $\mathrm{K}+\mathrm{N}$, and $\mathrm{K}+\mathrm{Zn}+\mathrm{N}$, compared to the $\mathrm{DW}+\mathrm{N}$, group (Figure 3 ). The lowest concentration of glucose was obtained in the group treated with deionized water only $(75.21 \pm 2.4 \mathrm{mg} / \mathrm{dl})$, whereas the group treated with DW $+\mathrm{N}$ had the highest concentration $(104.31 \pm 31 \mathrm{mg} / \mathrm{dl})$.

\subsection{Effects of treatments on concentration of serum protein fractions}

The serum total protein was decreased significantly $(p<.05)$ in the group treated with $\mathrm{DW}+\mathrm{N}$, compared to the $\mathrm{Zn}+\mathrm{K}+\mathrm{N}$ group. There was no significant $(p>.05)$ difference in serum total protein 


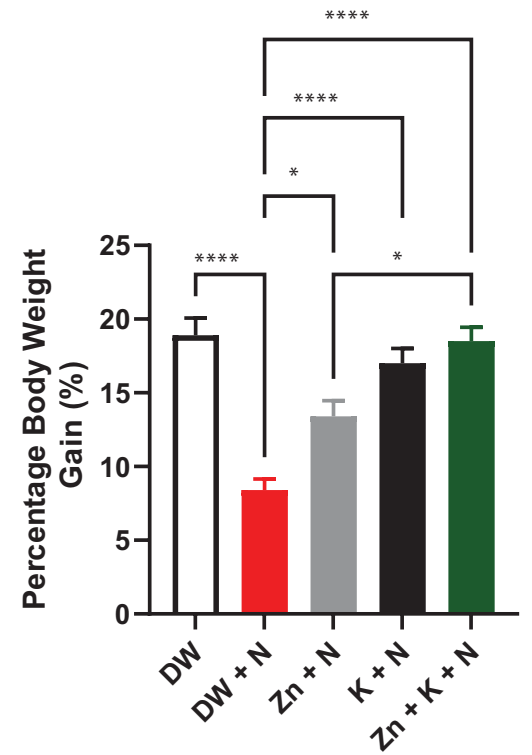

Figure 1. Effects of kaempferol and zinc gluconate on percentage body weight gain in male Wistar rats exposed to noise stress (mean \pm SEM, $n=7$ ). ${ }^{\star} p<.05$ and ${ }^{\star \star \star \star} p<.0001$ are significantly different compared to control group (DW $+\mathrm{N}$ ). DW, deionized water; K, kaempferol; N, noise; ZnG, zinc gluconate.

concentration in the $\mathrm{DW}+\mathrm{N}$ group, compared with $\mathrm{Zn}+\mathrm{N}$ and $\mathrm{K}+\mathrm{N}$ groups (Table 1). Serum albumin concentration was significantly higher $(p<.05)$ in the $\mathrm{K}+\mathrm{N}(3.89 \pm 0.21 ; 7.3 \%)$ and $\mathrm{Zn}+\mathrm{K}+\mathrm{N}$ $(3.93 \pm 0.15 ; 10.6 \%)$ groups, compared to the group treated with $\mathrm{DW}+\mathrm{N}$, which had the least serum albumin concentration $(1.73 \pm 0.13)$. There was no significant $(p>.05)$ difference in serum globulin concentration between the groups (Table 1 ). There was no statistically significant difference between $\mathrm{Zn}+\mathrm{K}+\mathrm{N}$ group and the DW group for all the assayed protein fractions.

\subsection{Effects of treatments on concentration of serum lipid fractions}

Cholesterol and triglyceride levels in serum was significantly lower $(p<.05)$ in the other groups except for $\mathrm{Zn}+\mathrm{N}$ group when compared to the $\mathrm{DW}+\mathrm{N}$ group. The lowest concentrations of cholesterol and triglyceride was detected in the DW group $(96.18 \pm 4.18 \mathrm{mg} / \mathrm{dl}$ and $119.04 \pm 3.57 \mathrm{mg} / \mathrm{dl}$, respectively) while the highest concentration was observed in the DW $+\mathrm{N}$ group $(168.54 \pm 9.26 \mathrm{mg} / \mathrm{dl}$ and $189.16 \pm 8.43 \mathrm{mg} / \mathrm{dl}$, respectively). The lowest high-density lipoprotein (HDL) concentration was detected in the $\mathrm{DW}+\mathrm{N}$ group $(17.42 \pm 1.14 \mathrm{mg} / \mathrm{dl})$ while $\mathrm{Zn}+\mathrm{K}+\mathrm{N}$ group had the highest concentration $(34.17 \pm 1.04 \mathrm{mg} / \mathrm{dl})$. The difference in the levels of HDL between these two groups was statistically significant $(p<.05)$. The highest level of low-density lipoprotein (LDL) was seen in the $\mathrm{DW}+\mathrm{N}$ group $(110.67 \pm 4.23 \mathrm{mg} / \mathrm{dl})$, and this was significantly higher $(p<.05)$ compared to the other groups. The lowest LDL level was obtained in the DW group $(32.43 \pm 1.27 \mathrm{mg} / \mathrm{dl})$. There was no statistically significant difference between $\mathrm{Zn}+\mathrm{K}+\mathrm{N}$ group and the DW group for all the assayed lipid fractions (Table 2).

\subsection{Effects of treatment on MDA Concentration}

The MDA concentration decreased significantly $(p<.05)$ in rat groups treated with kaempferol + zinc gluconate + noise $(0.64 \pm 0.20 \mathrm{nmol} / \mathrm{mg})$, compared to the concentrations recorded in deionized water + noise group $(1.0 \pm 0.20 \mathrm{nmol} / \mathrm{mg})$, which was significantly $(p<.05)$ higher than in both the 
A

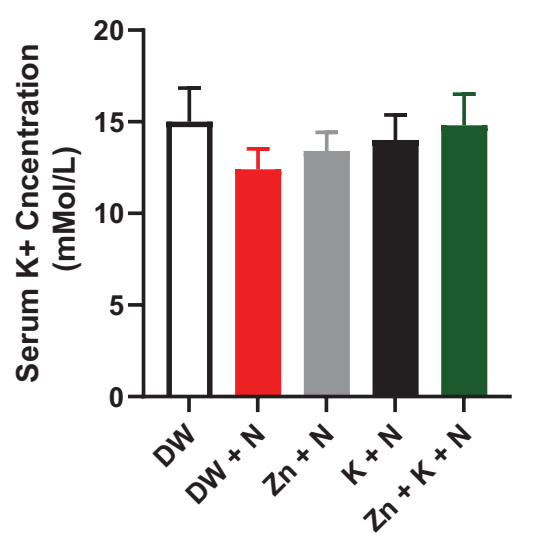

C

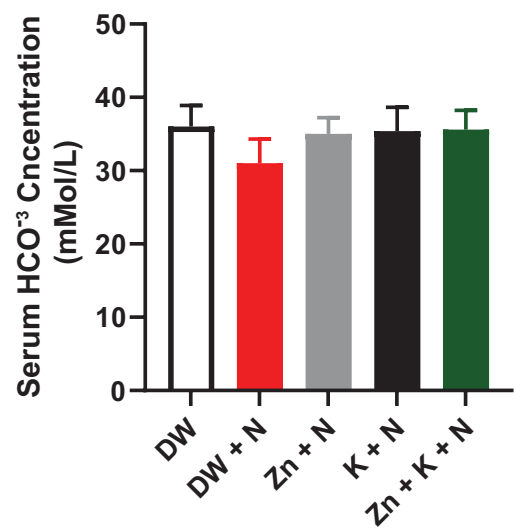

B

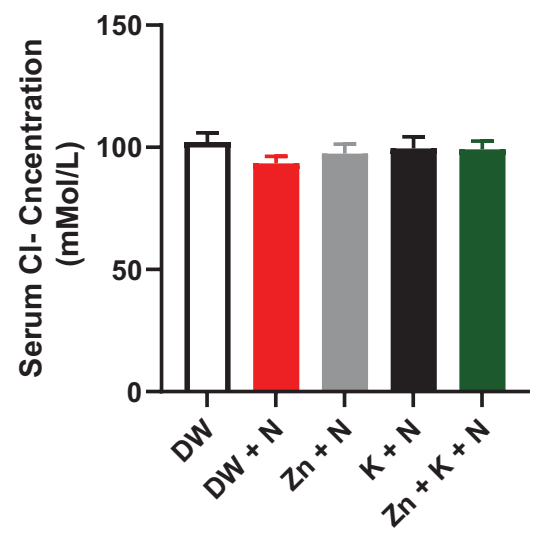

D

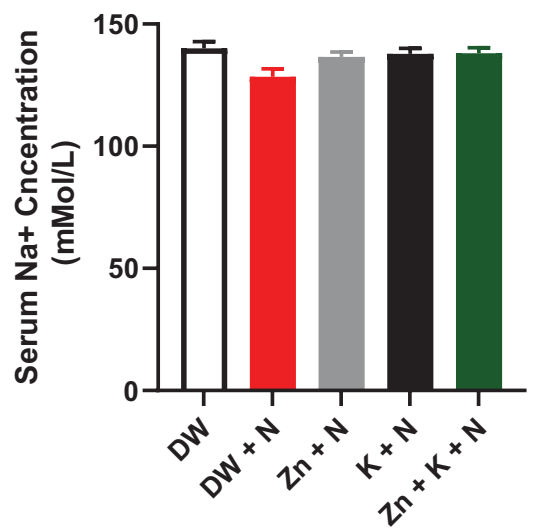

Figure 2. Effects of kaempferol and zinc gluconate on serum electrolyte concentration ( $\left.\mathrm{mMol} / \mathrm{L}^{-}\right)$in Wistar rats exposed to noise stress. (a) Potassium $\left(\mathrm{K}^{+}\right)$, (b) chloride $\left(\mathrm{Cl}^{-}\right)$, (c) bicarbonate $\left(\mathrm{HCO}^{-3}\right)$, and (d) sodium $\left(\mathrm{Na}^{+}\right)$. DW, deionized water; $\mathrm{K}$, kaempferol; N, noise; $\mathrm{Zn}$, zinc gluconate (mean $\pm \mathrm{SEM}, n=7$ ).

deionized water-treated group $(0.62 \pm 0.10 \mathrm{nmol} / \mathrm{mg})$ and kaempferol + noise group $(0.64 \pm 0.20 \mathrm{nmol} /$ $\mathrm{mg})$. The difference in MDA concentrations between the group administered with deionized water and that treated with kaempferol + zinc gluconate + noise was insignificant.

\subsection{Relationship between MDA concentration and body weight gain}

A strong correlation was observed between the concentration of MDA and body weight gain in the different treatment groups. Pearson's correlation coefficient of $r=0.7570$ and $p=.0001$ was observed (Figure 4).

\section{Discussion}

Variation in body weight gain alongside biochemical parameters is considered vital for the assessment of stress and degree of oxidative impairment. Results from this study showed that the body weight gain of 
A

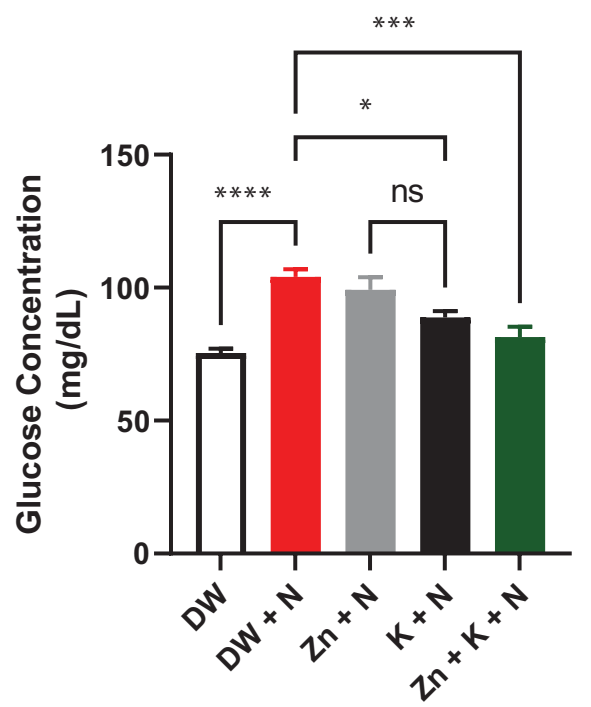

B

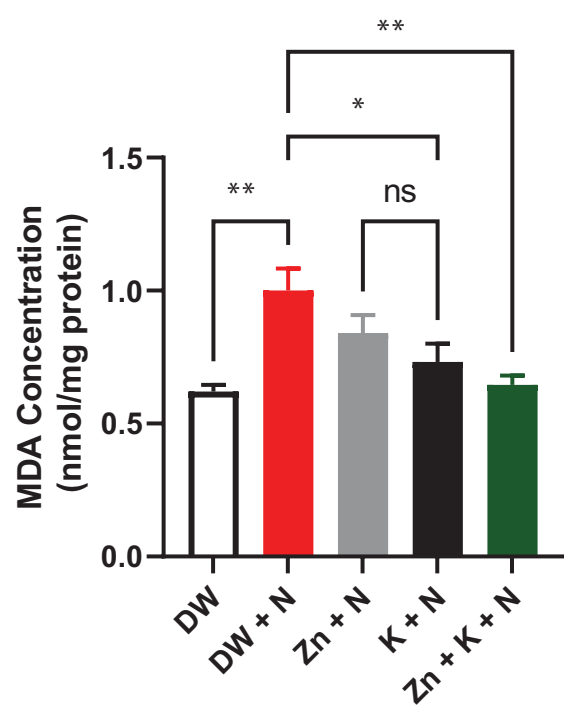

Figure 3. Effects of kaempferol and zinc gluconate on serum (a) glucose concentration (mg/dl) and (b) malondialdehyde concentration (MDA) (nmol/mg) in Wistar rats exposed to noise stress (mean \pm SEM, $n=7) .{ }^{\star} p<.05,{ }^{\star \star} p<.01,{ }^{\star \star \star} p<.001$, and ${ }^{\star \star \star \star} p<.0001$ are significantly different compared to control group (DW + N). DW, deionized water; K, kaempferol; N, noise; Zn, zinc gluconate.

Table 1. Ameliorative effect of kaempferol and zinc gluconate on concentration of serum protein fractions (mg/dl) of Wistar rats exposed to noise stress (mean \pm SEM, $n=6$ )

\begin{tabular}{lccccc} 
& \multicolumn{5}{c}{ Groups } \\
\cline { 2 - 6 } Parameters $(\mathrm{mg} / \mathrm{dl})$ & DW & DW $+\mathrm{N}$ & $\mathrm{Zn}+\mathrm{N}$ & $\mathrm{K}+\mathrm{N}$ & $\mathrm{Zn}+\mathrm{K}+\mathrm{N}$ \\
\hline Total protein & $7.96 \pm 0.14^{\mathrm{a}}$ & $5.10 \pm 0.18$ & $6.10 \pm 0.10$ & $6.31 \pm 0.14$ & $7.91 \pm 0.13^{\mathrm{a}}$ \\
\hline Albumin & $3.76 \pm 0.51^{\mathrm{a}}$ & $1.73 \pm 0.13$ & $2.71 \pm 0.10$ & $3.89 \pm 0.21^{\mathrm{a}}$ & $3.93 \pm 0.15^{\mathrm{a}}$ \\
\hline Globulin & $4.02 \pm 0.02$ & $3.79 \pm 0.14$ & $3.86 \pm 0.33$ & $3.95 \pm 0.97$ & $4.00 \pm 0.01$ \\
\hline
\end{tabular}

Abbreviations: DW, deionized water; K, kaempferol; N, noise; Zn, zinc gluconate.

${ }^{a}$ Values that are significantly $(p<.05)$ different compared to the $\mathrm{DW}+\mathrm{N}$ group.

male rats was significantly decreased in the group exposed to noise without antioxidant treatment, indicating that noise exerts a negative effect on the growth and development of rats. This corroborates previously reported studies (Jalali et al., 2012; Taban et al., 2017) which affirm the inhibitory effect of noise on body weight gain in exposed subjects. Our results demonstrate that co-administration of kaempferol and zinc gluconate significantly improved noise-induced deficit in body weight gain observed in the exposed rats. To the best of our knowledge, this is the first time this has been reported. The mechanism by which this antioxidant assortment exerts its effect may be by improving basal metabolism, appetite, and gastrointestinal motility in the treated rats (Isaac, Ibrahim, et al., 2017; Zhang et al., 2015).

The dyshomeostasis observed in some of the biochemical parameters evaluated in the present study indicates that aside from noise-induced hearing loss, noise induces other biochemical perturbations in the exposed animals. The observation of no significant change in serum electrolyte concentrations recorded in this study corroborates the report of Zare et al. (2016), who reported that occupational noise 
Table 2. Ameliorative effect of kaempferol and zinc gluconate on concentration of serum lipid fractions (mg/dl) in Wistar rats exposed to noise stress (mean $\pm \mathrm{SEM}, n=6$ )

\begin{tabular}{lccccc}
\hline & \multicolumn{5}{c}{ Groups } \\
\cline { 2 - 6 } Parameters $(\mathrm{mg} / \mathrm{dl})$ & $\mathrm{DW}$ & $\mathrm{DW}+\mathrm{N}$ & $\mathrm{Zn}+\mathrm{N}$ & $\mathrm{K}+\mathrm{N}$ & $\mathrm{Zn}+\mathrm{K}+\mathrm{N}$ \\
\hline Cholesterol & $96.18 \pm 4.18^{\mathrm{b}}$ & $168.54 \pm 9.26$ & $143.42 \pm 5.02$ & $124.15 \pm 5.28^{\mathrm{a}}$ & $103.84 \pm 4.24^{\mathrm{b}}$ \\
\hline Triglyceride & $119.04 \pm 3.57^{\mathrm{b}}$ & $189.16 \pm 8.43$ & $163.08 \pm 4.10$ & $142.70 \pm 5.23^{\mathrm{a}}$ & $126.27 \pm 8.15^{\mathrm{b}}$ \\
\hline HDL & $37.43 \pm 1.63^{\mathrm{a}}$ & $17.42 \pm 1.14$ & $19.63 \pm 1.43$ & $21.06 \pm 0.87$ & $34.17 \pm 1.04^{\mathrm{a}}$ \\
\hline LDL & $32.43 \pm 1.27^{\mathrm{b}}$ & $110.67 \pm 4.23$ & $88.67 \pm 5.28^{\mathrm{a}}$ & $72.10 \pm 4.83^{\mathrm{a}}$ & $39.97 \pm 1.17^{\mathrm{b}}$ \\
\hline
\end{tabular}

Abbreviations: DW, deionized water; HDL, high-density lipoprotein; K, kaempferol; LDL, low-density lipoprotein; N, noise; Zn, zinc gluconate. a,b Values with different superscript letters are significantly $(p<.05)$ different compared to the DW $+\mathrm{N}$ group.

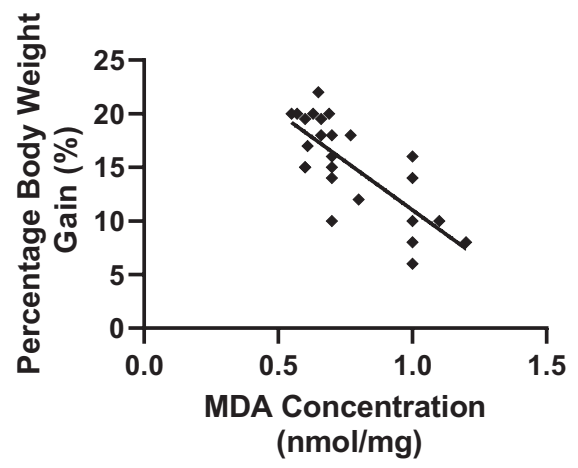

Figure 4. Relationship between MDA concentration and percentage body weight gain in Wistar rats exposed to noise stress (mean \pm SEM, $n=7$ ).

exposure had no significant effect on serum potassium electrolyte. However, the fact that there were marginal alterations in levels of electrolytes should not be totally ignored as this may indicate that noise exposure triggers some level of metabolic changes which is reflective of endogenous mechanisms of otoprotection in the exposed animals (Ji et al., 2019). Our study also revealed an increase in blood glucose levels in rats exposed to noise without any antioxidant treatment. This result suggests that noise affects glucose metabolism, which stems from the loss of insulin-sensitivity associated with noise exposure as seen in previous studies that highlighted the role of chronic noise exposure in diabetogenesis, and noiseassociated increase in blood lipid levels (also observed in our study; Dzhambov, 2015; Liu et al., 2018). The increased glucose level was reversed to normal in the group administered a combination of both antioxidants, and this gives credence to previous studies which suggested that kaempferol (Al-Numair et al., 2015) and zinc (Ranasinghe et al., 2015) possess antidiabetic properties, consequently, their combination yielded an improved effect.

Importantly, this study also demonstrated that chronic exposure to noise initiated considerable decrease in the concentration of serum total protein, partly owing to the detrimental effects of noise on the associated body tissues and hypoalbuminaemia because of a decrease in the synthesis of albumin by the liver following impaired hepatic function. Ji et al. (2019) submitted that impaired metabolism may signify oxidative damage and perturbed metabolism of protein, induced by noise. Co-administration of kaempferol and zinc gluconate improved the decreased levels of serum total protein and albumin, arising from noise exposure.

Previously, Melamed et al. (1997) reported a significantly higher levels of cholesterol, triglyceride, LDL, and HDL, mainly in younger men exposed to high industrial noise. Similarly, our study showed a 
significant increase in cholesterol, triglyceride, LDL, and HDL in rats exposed to noise. This alteration in serum lipid concentrations may be attributed to impairment of the metabolism of lipids alongside increased peroxidation of membrane lipids, associated with noise exposures (Akefe et al., 2019; Karafakioğlu, 2019). Co-administration of kaempferol and zinc gluconate in noise-exposed rats, ameliorated the increase in serum lipids observed in this study, thus suggesting their potential in maintaining metabolic homeostasis.

The increase in MDA concentration demonstrated that noise stress induced an increase in ROSinduced cell damage and death (Henderson et al., 2006; Lamidi et al., 2020; Zhang et al., 2015). The significant decrease in MDA observed in the group treated with kaempferol + zinc gluconate, compared to the groups separately treated with kaempferol and zinc gluconate, indicated that combination of kaempferol and zinc yielded an improved outcome in ameliorating the adverse effects of noise stress, induced via increased lipid peroxidation (Tu et al., 2007). The result of the present study also agrees with those of Khalaf et al. (2017) and Nunes et al. (2017), who reported that zinc supplementation considerably increases activities of oxidative stress-related enzymes and stabilizes the concentration of MDA, thus signifying its antiperoxidative potential. Overall, the result of the present study demonstrates that consumption of foods, containing the antioxidants, kaempferol, and zinc, may be beneficial to high noise-risk populations.

\section{Conclusion}

Exposure of Wistar rats to noise significantly decreased body weight gain and altered the concentrations of serum lipid and protein fractions. Treatment with kaempferol and/or zinc ameliorated noise-induced alteration in body weight gain, serum glucose, lipid and protein, and MDA levels. This suggests that biochemical dyshomeostasis and lipid peroxidation may be involved in the molecular mechanism underlying noise stress. Single administration of kaempferol was more effective than zinc gluconate, while their assortment produced an improved outcome in mitigating the adverse effects of noise stress in Wistar rats.

Acknowledgments. The authors would like to acknowledge the Faculty of Veterinary Medicine, Ahmadu Bello University, Zaria, for providing the facilities used for this research.

Funding Statement. This research received no specific grant from any funding agency, commercial or not-for-profit sectors.

Conflict of Interest. The authors declare no conflict of interest.

Authorship Contributions. J.O.A. and I.O.A. conceived and designed the study. V.O.S., I.O.A., and J.O.A. conducted data gathering, V.O.S. performed statistical analyses, V.O.S., J.O.A., and I.O.A. wrote the article.

Data Availability Statement. The authors confirm that the data supporting the findings of this study are available within the article.

\section{References}

Akefe, I. O., Ayo, J. O., \& Sinkalu, V. O. (2020). Kaempferol and zinc gluconate mitigate neurobehavioral deficits and oxidative stress induced by noise exposure in Wistar rats. PLoS One, 15, e0236251. https://doi.org/10.1371/journal.pone.0236251

Akefe, I. O., Yusuf, I. L., \& Adegoke, V. A. (2019). C-glycosyl flavonoid orientin alleviates learning and memory impairment by radiofrequency electromagnetic radiation in mice via improving antioxidant defence mechanism. Asian Pacific Journal of Tropical Biomedicine, 9, 518.

Al-Numair, K. S., Chandramohan, G., Veeramani, C., \& Alsaif, M. A. (2015). Ameliorative effect of kaempferol, a flavonoid, on oxidative stress in streptozotocin-induced diabetic rats. Redox Report, 20, 198-209.

Andreini, C., \& Bertini, I. (2012). A bioinformatics view of zinc enzymes. Journal of Inorganic Biochemistry, 111, $150-156$.

Bigoniya, P., Singh, C., \& Shrivastava, B. (2013). In vivo and in vitro hepatoprotective potential of kaempferol, a flavone glycoside from Capparis spinosa. International Journal of Pharma and Biological Sciences, 3, 139-152.

Draper, H. H., \& Hadley, M. (1990). [43] Malondialdehyde determination as index of lipid peroxidation. Methods in Enzymology, 186, 421-431.

Dzhambov, A. M. (2015). Long-term noise exposure and the risk for type 2 diabetes: A meta-analysis. Noise \& Health, 17, 23. 
Floud, S., Blangiardo, M., Clark, C., de Hoogh, K., Babisch, W., Houthuijs, D., Swat, W., Pershagen, G., Katsouyanni, K., Velonakis, M., Vigna-Taglianti, F., Cadum, E., \& Hansell, A. L. (2013). Exposure to aircraft and road traffic noise and associations with heart disease and stroke in six European countries: A cross-sectional study. Environmental Health, 12, 1-11.

GBD 2019 Hearing Loss Collaborators. (2021). Hearing loss prevalence and years lived with disability, 1990-2019: Findings from the Global Burden of Disease Study 2019. The Lancet, 397, 996-1009.

Henderson, D. C., Borba, C. P., Daley, T. B., Boxill, R., Nguyen, D. D., Culhane, M. A., Louie, P., Cather, C., Evins, A. E., Freudenreich, O., Taber, S. M., \& Goff, D. C. (2006). Dietary intake profile of patients with schizophrenia. Annals of Clinical Psychiatry, 18, 99-105.

Isaac, A., Ibrahim, Y., Andrew, A., Ibrahim, Y., Edward, D., \& Solomon, A. (2017). The cortisol steroid levels as a determinant of health status in animals. Journal of Proteomics \& Bioinformatics, 10, 277-283.

Isaac, A. O., Joseph, A. O., Victor, S. O., Lamidi, Y. I., \& Andrew, A. M.. (2017). Ameliorative effects of kaempferol and zinc gluconate on erythrocyte osmotic fragility and haematological parameters in Wistar rats exposed to noise stress. Insights in Biomedicine, 2, 15.

Jalali, M., Saki, G., Sarkaki, A. R., Karami, K., \& Nasri, S. (2012). Effect of noise stress on count, progressive and nonprogressive sperm motility, body and genital organ weights of adult male rats. Journal of Human Reproductive Sciences, 5, 48.

Ji, L., Lee, H.-J., Wan, G., Wang, G.-P., Zhang, L., Sajjakulnukit, P., Schacht, J., Lyssiotis, C. A., \& Corfas, G. (2019). Auditory metabolomics, an approach to identify acute molecular effects of noise trauma. Scientific Reports, 9, 1-9.

Karafakioğlu, Y.S. (2019). Effects of $\alpha$ lipoic acid on noise induced oxidative stress in rats. Saudi Journal of Biological Sciences, 26, 989-994.

Khalaf, A., Ibrahim, M., Tohamy, A., Allah, A., \& Zaki, A. R. (2017). Protective effect of vitazinc on chlorsan induced oxidative stress, genotoxicity and histopathological changes in testicular tissues of male rats. International Journal of Pharmacology, 13(1), 22-32.

Lamidi, I. Y., Hudu, M. G., Akefe, I. O., Adamu, S., \& Salihu, S. I. (2020). Sub-chronic administration of flavonoid fraction daflon improve lead-induced alterations in delta-aminolevulinic acid dehydratase activity, erythrocytic parameters, and erythrocyte osmotic fragility in Wistar rats. Comparative Clinical Pathology, 29, 955-963.

Langeswaran, K., Selvaraj, J., Ponnulakshmi, R., Mathaiyan, M., \& Vijayaprakash, S. (2018). Protective effect of kaempferol on biochemical and histopathological changes in mercuric chloride induced nephrotoxicity in experimental rats. Journal of Biologically Active Products from Nature, 8, 125-136.

Liu, L., Huang, Y., Fang, C., Zhang, H., Yang, J., Xuan, C., Wang, F., Lu, H., Cao, S., Wang, Y., Li, S., Sha, J., Zha, M., Guo, M., \& Wang, J. (2018). Chronic noise-exposure exacerbates insulin resistance and promotes the manifestations of the type 2 diabetes in a high-fat diet mouse model. PLoS One, 13, e0195411.

Marreiro, D. D. N., Cruz, K. J. C., Morais, J. B. S., Beserra, J. B., Severo, J. S., \& De Oliveira, A. R. S. (2017). Zinc and oxidative stress: Current mechanisms. Antioxidants, 6, 24.

Melamed, S., Froom, P., Kristal-Boneh, E., Gofer, D., \& Ribak, J. (1997). Industrial noise exposure, noise annoyance, and serum lipid levels in blue-collar workers-The CORDIS Study. Archives of Environmental Health: An International Journal, 52, 292-298.

Moslehi, A., Nabavizadeh, R. F., Keshavarz, M., Rouhbakhsh, N., Sotudeh, M., \& Salimi, E. (2010). Traffic noise exposure increases gastric acid secretion in rat. Acta medica Iranica, 48(2), 77-82.

Nunes, R., Pasko, P., Tyszka-Czochara, M., Szewczyk, A., Szlosarczyk, M., \& Carvalho, I. S. (2017). Antibacterial, antioxidant and anti-proliferative properties and zinc content of five south Portugal herbs. Pharmaceutical Biology, 55, 114-123.

Prasad, A. S. (2014). Impact of the discovery of human zinc deficiency on health. Journal of Trace Elements in Medicine and Biology, 28(4), 357-363.

Ranasinghe, P., Pigera, S., Galappatthy, P., Katulanda, P., \& Constantine, G. R. (2015). Zinc and diabetes mellitus: Understanding molecular mechanisms and clinical implications. DARU Journal of Pharmaceutical Sciences, 23, 1-13.

Saki, G., Jalali, M. A., Sarkaki, A. R., Karami, K., \& Ahangarpoor, A. (2016). Effect of supplementation of zinc on fertilization capacity of male rats exposed to noise stress. International Journal of Pharmaceutical Research and Allied Sciences, 5, 67-74.

Taban, E., Mortazavi, S. B., Vosoughi, S., Khavanin, A., \& Asilian Mahabadi, H. (2017). Noise exposure effects on blood glucose, cortisol and weight changes in the male mice. Health Scope, 6Placeholder Text, e36108.

Tu, Y.-C., Lian, T.-W., Yen, J.-H., Chen, Z.-T., \& Wu, M.-J. (2007). Antiatherogenic effects of kaempferol and rhamnocitrin. Journal of Agricultural and Food Chemistry, 55, 9969-9976.

Wankhar, D., Sheela Devi, R., \& Ashok, I. (2014). Emblica officinalis outcome on noise stress induced behavioural changes in Wistar albino rats. Biomedicine \& Preventive Nutrition, 4, 219-224. https://doi.org/10.1016/j.bionut.2013.12.011

Yasuno, F., Tanimukai, S., Sasaki, M., Ikejima, C., Yamashita, F., Kodama, C., Mizukami, K., \& Asada, T. (2012). Combination of antioxidant supplements improved cognitive function in the elderly. Journal of Alzheimer's Disease, 32 895-903. 
Zare, S., Nassiri, P., Monazzam, M. R., Pourbakht, A., Azam, K., \& Golmohammadi, T. (2016). Evaluation of the effects of occupational noise exposure on serum aldosterone and potassium among industrial workers. Noise \& Health, 18(80), 1.

Zhang, L., Gong, J. T., Zhang, H. Q., Song, Q. H., Xu, G. H., Cai, L., Tang, X. D., Zhang, H. F., Liu, F.-E., Jia, Z. S., \& Zhang, H. W. (2015). Melatonin attenuates noise stress-induced gastrointestinal motility disorder and gastric stress ulcer: Role of gastrointestinal hormones and oxidative stress in rats. Journal of Neurogastroenterology and Motility, 21, 189.

Cite this article: Akefe IO, Ayo JO, Sinkalu VO (2021). Assortment of kaempferol and zinc gluconate improves noiseinduced biochemical imbalance and deficits in body weight gain. Experimental Results, 2, e37, 1-13. https://doi.org/10.1017/ exp. 2021.30 


\section{Peer Reviews}

\section{Reviewing editor: Dr. Michael Nevels}

University of St Andrews, Biomolecular Sciences Building, Fife, United Kingdom of Great Britain and Northern Ireland, KY16 9ST

This article has been accepted because it is deemed to be scientifically sound, has the correct controls, has appropriate methodology and is statistically valid, and has been sent for additional statistical evaluation and met required revisions.

doi:10.1017/exp.2021.30.pr1

Review 1: Assortment of kaempferol and zinc gluconate improves noise-induced biochemical imbalance and deficits in body weight gain in Wistar rats

Reviewer: Dr. Adil Mehraj Khan iD

Sher-e-Kashmir University of Agricultural Sciences

Date of review: 17 September 2021

(c) The Author(s), 2021. Published by Cambridge University Press. This is an Open Access article, distributed under the terms of the Creative Commons Attribution licence (http://creativecommons.org/licenses/by/4.0), which permits unrestricted re-use, distribution and reproduction, provided the original article is properly cited.

Conflict of interest statement. Reviewer declares none

Comments to the Author: As kaempferol is insoluble in water, why was deionized water used as its vehicle and administered to control group as vehicle control? Improper solubility of kaempferol in this vehicle also questions the homogeneity of dosage between different rats.

Important parameters of ambient stress like cortisol level, T-4/ T-3 level, heat shock proteins should be determined.

Results of feed intake is missing.

Levels of leptin should be assayed.

What about the weight of different organs?

How did authors access the hearing loss in the rats as is claimed in the manuscript?

How do authors justify oxidative imbalance just by assaying LPO and excluding several other parameters of oxidative stress?

Page 5 line 125-126 is not clear. It seems contradictory to the preceding sentence.

Different superscripts should be provided on the result of different groups presented in figures/ tables. Every group should be statistically compared with other groups.

Overall the study is too superficial.

\section{Score Card}

Presentation

Is the article written in clear and proper English? (30\%)

Is the data presented in the most useful manner? (40\%)

Does the paper cite relevant and related articles appropriately? (30\%) 
Does the abstract correctly embody the content of the article? (25\%)

Does the introduction give appropriate context? (25\%)

Is the objective of the experiment clearly defined? (25\%)

Analysis

Does the discussion adequately interpret the results presented? (40\%)

Is the conclusion consistent with the results and discussion? (40\%)

Are the limitations of the experiment as well as the contributions of the experiment clearly outlined? (20\%) 


\section{Review 2: Assortment of kaempferol and zinc gluconate improves noise-induced biochemical imbalance and deficits in body weight gain in Wistar rats}

Reviewer: Dr. Ibrahim Yusuf Lamidi

University of Maiduguri Faculty of Veterinary Medicine, Pharmacology and Toxicology, Zaria, Kaduna, Nigeria

Date of review: 12 September 2021

(c) The Author(s), 2021. Published by Cambridge University Press. This is an Open Access article, distributed under the terms of the Creative Commons Attribution licence (http://creativecommons.org/licenses/by/4.0), which permits unrestricted re-use, distribution and reproduction, provided the original article is properly cited.

Conflict of interest statement. Reviewer declares none

Comments to the Author: I have provided my comments as follows;

The authors have achieved their objective and the manuscript in generally speaking, well-written.

I will however advise the authors to go through the manuscript once more to ensure that any grammatical error is corrected to enhance clarity.

Also it will be good if the authors could include more recent references as well as specify limitations of the study if any.

\section{Score Card}

Presentation

Is the article written in clear and proper English? (30\%)

Is the data presented in the most useful manner? (40\%)

Does the paper cite relevant and related articles appropriately? (30\%)

Context

Does the title suitably represent the article? (25\%)

Does the abstract correctly embody the content of the article? (25\%)

Does the introduction give appropriate context? (25\%)

Is the objective of the experiment clearly defined? (25\%)

Analysis

Are the limitations of the experiment as well as the contributions of the experiment clearly outlined? (20\%) 